\title{
A Valorização da Ruralidade a partir do Turismo: Roteiro Turístico Caminhos Rurais, Porto Alegre, Rio Grande do Sul, Brasil ${ }^{1}$
}

\author{
The Rurality Valorization from Tourism: Touristic Itinerary of Rural Routes, Porto \\ Alegre, Rio Grande do Sul, Brazil
}

\author{
Andressa Ramos Teixeira (TEIXEIRA, A. R.) ${ }^{*}$ e Marcelino de Souza (Souza, M. de S.) ${ }^{* *}$
}

\begin{abstract}
RESUMO - O turismo no espaço rural ao ter nas particularidades sociais, culturais e espaciais do rural seus atrativos, pode propiciar a valorização deste meio, ao ter seu desenvolvimento condicionado à conservação ambiental, patrimonial, cultural. Nesse contexto, o presente estudo analisou o turismo rural enquanto agente atuante sobre a valorização da ruralidade no município de Porto Alegre, Rio Grande do Sul, Brasil, a partir do Roteiro Turístico Caminhos Rurais. A pesquisa esteve balizada pela abordagem qualitativa, tendo como base de análise entrevistas semiestruturadas, aplicadas a proprietários rurais inseridos no roteiro. A apreciação demonstrou que o turismo vem gerando a valorização do rural em Porto Alegre, a partir da divulgação do modo de produção, dos produtos e da paisagem. Além disso, o turismo, assim como valoriza elementos da ruralidade, também sustenta a aproximação do rural com a urbanidade ao ser mais uma atividade originada no urbano se apropriando do campo e atuando sobre as ruralidades, mas a atuação do turismo no rurbano de Porto Alegre aproxima este espaço a uma perspectiva de continuиm que favorece a interação entre esses dois ambientes, e não a tomada de um pelo outro.
\end{abstract}

Palavras-chave: Turismo Rural; Ruralidade; Desenvolvimento Rural; Multifuncionalidade.

ABSTRACT - Because tourism has in rural space its own attractions in social, cultural, and spatial particularities, it can propitiate the valorization of the rural environment since it has its development conditioned by environmental, patrimonial, and cultural preservation. In this context, the current study analyzed rural tourism as an acting agent on the valorization of the rurality in Porto Alegre municipality, Rio Grande do Sul, Brazil, parting from the Touristic Itinerary of Rural Routes. The research is based on the qualitative approach, which has as basis the analysis of semi-structured interviews, applied to rural farmers inserted in the itinerary. The appreciation demonstrated that the tourism has caused the valorization of the rural areas in Porto Alegre, due to the divulgation of the production means, the products and the rural landscape. Moreover, the tourism, just as it values elements of the rurality, it also sustains the approximation of the rural areas with the urban ones, which appropriates the rural space and acts on the ruralities; but the action of tourism in the Porto Alegra rururban approximates such space to a perspective of continuum which helps the interaction between the rural and the urban areas, and not the domination of the urban by the rural.

Key words: Rural tourism; Rurality, Rural development; Multi-functionality.

\footnotetext{
${ }^{1}$ Este trabalho insere-se em uma pesquisa mais ampla, denominada "Benefícios e Desafios do Turismo Rural para os Agricultores Familiares: estudo em dois roteiros do Estado do Rio Grande do Sul", sendo esta financiada pelo Conselho Nacional de Desenvolvimento Científico e Tecnológico (CNPQ).
}

* Graduação em Geografia (Licenciatura) pela Universidade Federal de Santa Maria (UFSM). Mestrado em Desenvolvimento Rural pelo Programa de Pós-Graduação em Desenvolvimento Rural da Universidade Federal do Rio Grande do Sul (UFRGS). Membro do Grupo de Pesquisa Mercados NãoAgrícolas Rurais. Endereço: Avenida João Pessoa, 31, sala 12 (Centro). CEP: 90040-000 - Porto Alegre Rio Grande do Sul (Brasil). Telefone/Fax: 51-3308-3281. E-mail: andressart@ gmail.com

** Graduação em Agronomia pela Universidade Estadual de Londrina (UEL). Mestrado em Extensão Rural pela Universidade Federal de Santa Maria (UFSM). Doutorado em Engenharia Agrícola pela Universidade de Campinas (UNICAMP). Professor da Faculdade de Ciências Econômicas e do Programa de Pós-Graduação em Desenvolvimento Rural (UFRGS). Coordenador do Grupo de Pesquisa Mercados Não-Agrícolas Rurais. Endereço: Avenida João Pessoa, 31, sala 12 (Centro). CEP: 90040-000 - Porto Alegre - Rio Grande do Sul (Brasil). Telefone/Fax: 51-3308-3281. E-mail: marcelino.souza@ uol.com.br 


\section{INTRODUÇÃO}

O turismo vem incorporando as transformações que gradualmente e constantemente acompanham a história da sociedade mundial. Desta forma, as características que permeiam a sociedade contemporânea promovem a constante expansão do turismo, de modo que esta atividade abarque diferentes espaços e diversas esferas, tais como: sociocultural, ambiental e econômica, fazendo com que o turismo desponte como uma atividade promotora de desenvolvimento que transcende o econômico.

Dentre os diferentes espaços que vem incorporando o turismo, mais recentemente, se encontram os espaços rurais. A chegada do turismo às áreas rurais surge como alternativa socioeconômica para os agricultores e uma opção de lazer para aqueles que procuram atividades turísticas diferenciadas. Por conseguinte, visto que o turismo é uma atividade que origina uma série de dinâmicas nos locais que o incorporam, proporcionando perspectivas para a melhoria da qualidade de vida de populações rurais, este pode estar atuando como promotor do desenvolvimento de comunidades rurais.

Nesse contexto de mudanças, os estudos realizados sobre os espaços rurais, na atualidade, abordam crescentemente os temas vinculados às "novas ruralidades", pautando-se, assim, em questionamentos sobre o que é o rural, qual sua dimensão espacial, social, cultural, econômica e ambiental. Essas reflexões sobre a ruralidade emergente insurgem conjuntamente a um panorama de mudanças em que a adesão às atividades não agrícolas como meio de ocupação da população rural ganha cada vez mais destaque. Dentre elas, a crescente implantação de atividades turísticas em espaços rurais como meio de desenvolver e revitalizar comunidades rurais, nas mais diferentes esferas, faz com que o turismo desponte entre as atividades não agrícolas rurais a que ganha maior notoriedade.

Esta crescente inserção do turismo no meio rural tem ocorrido tanto por iniciativas de comunidades como de órgãos públicos, que buscam, nas possíveis influências trazidas pelo turismo, a dinamização de comunidades rurais. Pois o turismo, se planejado sob a ótica do desenvolvimento local, pode, como poucas outras atividades, trazer benefícios de cunho ambiental, cultural e social. Visto que a tendência 
da entrada em espaços rurais de atividades não agrícolas vem acompanhada de uma nova significação atribuída aos espaços rurais, na qual este deixa de ser visto tãosomente como o espaço onde se produz bens primários, passa também a ser visto como um espaço de conservação ambiental, patrimonial e de valores culturais.

Assim, o turismo no espaço rural ao ter nas particularidades socioculturais e naturais os seus atrativos, propicia a valorização do meio rural, condicionada à conservação ambiental, patrimonial, cultural etc., e traz conjuntamente uma nova função a este espaço. Dessa forma, o turismo tem capacidade de atrelar à valorização do meio rural uma função econômica. Neste sentido, Mattei (2004, p. 198) ressalta que "[...] as atividades turísticas que estão sendo desenvolvidas no meio rural visam, sobretudo, à geração de empregos, o incremento na renda e à própria valorização do meio rural.”.

Para tanto, este artigo propõe-se à análise do turismo enquanto agente capaz de promover a valorização do rural, no que concernem os aspectos culturais, de produção e naturais, auxiliando na manutenção dos elementos que o caracterizam, diferenciando-o dos espaços urbanos. O foco de análise empírica foi o roteiro Caminhos Rurais, situado no município de Porto Alegre, Rio Grande do Sul, Brasil.

Estudar o turismo como agente promotor da valorização do rural no contexto do município de Porto Alegre justifica-se pela diferenciação que este apresenta em relação aos demais espaços rurais do estado do Rio Grande do Sul, pois conforme a Secretaria de Planejamento Municipal de Porto Alegre (PORTO ALEGRE, 1999) que elaborou o Plano Diretor de Desenvolvimento Urbano Ambiental (PDDUA) do município, Porto Alegre não tem mais um espaço rural e sim o que é chamado de "Cidade Rururbana", pois o espaço municipal onde assentam-se as propriedades rurais é também composto por núcleos urbanos. “Assim, atualmente, convivem, lado a lado, áreas de produção rural para subsistência e para comércio, sítios de lazer, pequenos comércios, algumas indústrias, núcleos habitacionais tipicamente urbanos ora estruturados ora não." (PORTO ALEGRE, 1999, s./n.).

Assim, o município de Porto Alegre vem sofrendo com a contínua expansão do espaço urbano em detrimento dos núcleos rurais. O que vem ocasionando a proximidade do homem rural com o espaço urbano, trazendo a esses novos valores, que podem influenciá-lo a imprimir, nesses espaços, elementos e formas que descaracterizam o rural, que causam uma série de alterações na dinâmica espacial e social local. Em 
contraponto, a Secretaria Municipal de Turismo de Porto Alegre (PORTO ALEGRE, 2005, p.3), ao implantar o roteiro turístico Caminhos Rurais tem como um de seus objetivos "Promover a conservação do patrimônio rural, ambiental e cultural, mantendo a paisagem natural da zona sul de Porto Alegre.”.

\section{MÉTODOS E TÉCNICAS}

O presente trabalho constitui-se num estudo de natureza descritiva, no qual se buscou abordar o fenômeno do turismo rural no roteiro denominado "Caminhos Rurais" situado na Zona Sul de Porto Alegre, município situado no estado do Rio Grande do Sul, região sul do Brasil, através de ferramentas qualitativas. Para tanto, a elaboração do trabalho apresentou as seguintes etapas: identificação da área de estudo, bem como de suas peculiaridades frente à temática de turismo rural; problematização e revisão bibliográfica do tema turismo rural (tanto no âmbito local quanto nas experiências já existentes); seleção da amostra da pesquisa; realização de entrevistas; e, por fim, a análise das informações coletadas.

A escolha do espaço de estudo se deu em função das características orientadoras do espaço geográfico na qual está situado o roteiro "Caminhos Rurais", que engloba agricultoras e agricultores familiares, onde, há alguns anos é desempenhada a atividade do turismo rural através de uma série de iniciativas que envolvem ações distintas neste campo como, por exemplo, o turismo rural pedagógico, o turismo com produção de produtos agroecológicos, turismo equestre, dentre outros.

A metodologia utilizada na coleta de dados baseia-se no método qualitativo, por meio de observação não participativa e entrevistas não estruturadas. Sendo que, a amostragem utilizada foi a não probabilística intencional, a qual, segundo Almeida (1989, p. 87) "[...] seleciona um grupo de elementos considerados típicos, em função das variáveis estudadas [...] O critério da escolha, neste tipo de amostra, é a razão e não o aleatório, mas a razão é fundada nos critérios pré-estabelecidos.”.

Para tanto, consideraram-se como critérios para a seleção da amostra: atores que se constituem enquanto agricultores familiares do espaço "rurbano" e empreendedores do turismo, participantes do roteiro "Caminhos Rurais". 
A coleta dos dados foi realizada com oito empreendedores do turismo, dos trinta e dois que integram o roteiro turístico estudado. A utilização de um roteiro de entrevistas semiestruturado teve como objetivo a obtenção de respostas que atendessem às indagações da pesquisa, a qual, na sua totalidade buscou averiguar as influências geradas pela atividade turística. Portanto, para traçar a análise esboçada neste texto foi feito um recorte em que foram extraídas as questões relativas às influências sobre a valorização do rural.

A análise dos dados ocorreu através da organização e interpretação das informações coletadas, a fim de responder ao objetivo proposto.

\section{INCURSÃO NA LITERATURA}

Nesta seção são desvendados alguns elementos da literatura que tangem o desenvolvimento rural e contemplam a conjuntura que redirecionou as visões sobre os espaços rurais e possibilitou a emergência do turismo e também a revalorização destes lugares. Para tanto, fez-se pertinente abordar as perspectivas que analisam o campo e sua relação com a cidade, visto que a valorização do rural a transcende e emerge também da população que reside nos espaços urbanos. Contempla-se ainda a abordagem das novas ruralidades, a qual analisa as novas configurações traçadas sobre o rural, em que a sua revalorização apresenta-se como elemento importante.

\subsection{OLHARES SOBRE O RURAL E O URBANO}

Os espaços rurais e urbanos são historicamente debatidos e vislumbrados em suas diferenças e relações, as quais estão em constante transformação, ensejando mudanças práticas e também de valores atribuídos aos mesmos. "Na cadência da mudança, espaços são transformados e se transformam. $\mathrm{O}$ aparente reflete a intensidade e a velocidade dessas transformações, revelando o multifacetado processo de mudança". (BAGLI, 2006, p. 81)

As diferenciações traçadas entre estes espaços referem-se a diversos aspectos, dentre os quais se salientam: às atividades econômicas difundidas em cada um destes 
espaços, em que o urbano aparece vinculado à indústria e o rural à produção primária; à densidade demográfica, alta em espaços urbanos e baixa em espaços rurais; a uma paisagem em que a ação humana explorou de forma diferenciada os recursos naturais, provocando mudanças distintas conforme sua intensidade; aos grupos sociais que refletem modos de vida específicos intimamente vinculados às características e condições de cada espaço.

Sobre as distinções entre espaços rurais e urbanos Bagli (2006) faz uma análise sobre a exploração da temporalidade, a qual ressalta o urbano como um espaço de transformação e renovação constante, em que o fluxo de pessoas e coisas acontece de forma constante. E observa o rural como um espaço em que as transformações acontecem em menor escala, expressando-se assim de maneira pouco fugaz.

Estas diferenças entre espaços rurais e urbanos são exploradas na academia em diferentes abordagens teóricas, as quais são arquitetadas para compreender as relações estabelecidas entre estes diferentes meios e em diferentes realidades, buscando se adequar aos processos de transformação, para que se possa assim compreender as realidades em curso. Dentre as abordagens que têm destaque na compreensão destas realidades estão a dicotômica e a do continuum.

A visão dicotômica entre o rural e o urbano, ou entre o campo e a cidade estabelece uma relação de contradição, em que diferentes olhares são traçados, um oriundo do urbano, onde este é tido como um espaço moderno, inovador, dinâmico, exercendo poder sobre o rural e em que o rural é visto numa posição extrema, ou seja, como um meio tradicional, atrasado, fornecedor de recursos e de função passiva. Mas há também a visão advinda daqueles que vivenciam e estudam os espaços rurais e a ruralidade, estabelecendo parâmetros opostos e vendo o rural como um todo harmonioso, estável e de relações de cooperação e o urbano na posição extrema, como fonte de todos os males. (VEIGA, 2005).

Já a abordagem do continuum busca nas diferenças entre o campo e a cidade uma relação de complementaridade e não de oposição e que, conforme Wanderley (2001) é utilizada em duas vertentes. A primeira seria centrada no urbano, sendo este fonte de progresso, enquanto o pólo rural seria expressão do atraso, estando fadado, a partir da relação e aproximação com o urbano, à redução pela expansão deste. Juntamente com a teoria da urbanização do campo, esta visão do continuum traduziria o 
fim da realidade rural. A segunda vertente do continuum, e que se afasta mais da visão dicotômica, seria aquela que aproxima o rural-urbano, pois, mesmo com a aproximação de suas semelhanças, suas peculiaridades não desaparecem: aqui é reafirmada a existência do rural. Corroborando a autora destaca que:

Se a vida local é o resultado do encontro entre o rural e o urbano, o desenvolvimento local, entendido como o processo de valorização do potencial econômico, social e cultural da sociedade local, não pode supor o fim do rural. Neste sentido, é importante precisar que o desenvolvimento local será tanto mais abrangente e eficaz quanto for capaz de incorporar e valorizar o potencial de forças sociais para o desenvolvimento presentes no meio rural local, isto é, incorporar o próprio desenvolvimento rural. (WANDERLEY, 2001, p. 34).

Nesse contexto de transformação, em que os espaços mudam em si e influenciam espaços exógenos, onde as mudanças ocorrem de forma interligada, o rural atinge outra representação na totalidade socioespacial.

\subsection{DA ANTIGA AS NOVAS RURALIDADES}

Em tempos anteriores a noção de ruralidade, intimamente permeada pela visão dicotômica rural-urbano, apresentava o rural como o espaço de produção agrícola, de atraso e residual ao urbano. Atualmente, sob a égide de outras perspectivas teóricas, tal como a do continuum, e na consonância de outra conjuntura, a ruralidade ganha outras expressões.

Para Saraceno (1996), a ruralidade tem um caráter territorial imbricado que deve considerar a crescente diversidade apresentada entre os diferentes espaços rurais. Assim, atualmente, é precário ver o rural como o meio das atividades primárias, pura e simplesmente, ou mesmo como o oposto ou resíduo dos espaços urbanos, devendo-se compreender o rural em sua heterogeneidade. Nesse sentido, para Saraceno (1996, s./n.), "Há necessidade de repensar as tipologias de áreas não apenas sobre a base da diversificação interna das áreas, mas também sobre a base das ligações externas que as zonas rurais conseguem estabelecer".

É com base nessas novas dinâmicas que estão crescentemente sendo inseridas nos espaços rurais que vem se traçando novos olhares sobre a ruralidade. Sobre essas novas visões direcionadas as zonas rurais, Baptista (2006, p. 85) descreve que: 


\begin{abstract}
Os contornos do rural já não coincidem com a agricultura e a sua diversidade deixou de ser marcada pela geografia dos sistemas agrários ou, em formulações mais elaboradas, pela conjugação destes com os modos de vida e de trabalho, e também com os condicionalismos climáticos, orográficos e geológicos.
\end{abstract}

Esses novos contornos passam a ser moldados, em parte, por novas relações estabelecidas entre o rural e o urbano, em que a valorização das diferenças não mais tem o fim de esboçar uma relação antagônica, mas de complementaridade. Nesse sentido, cabe ressaltar Moreira (2007, p. 228) em sua análise sobre a importância do não-rural para que se tenha uma ruralidade: "O uno requer o diverso, o individuo só existe na relação social. A identidade rural requer a existência do não-rural. Nesse sentido, as ruralidades só podem existir e serem pensadas a partir de suas relações com algo que a cultura significa como não-rural."

Assim, a intensificação da relação entre cidade e campo se fortalece a partir de suas peculiaridades, buscando no outro o que não se produz no seu cotidiano, mas promove também a construção de hábitos comuns, o que não significa a destruição de seu modo de vida, ou de um processo de homogeneização. Pois, cada espaço, visto suas condições, impõe determinados hábitos que conduzem determinado modo de vida. (BAGLI, 2006).

Observa-se, neste contexto, que a visão dualista estabelecida entre os espaços rurais e urbanos não prevalece mais sobre as abordagens teóricas que contemplam as análises em torno da ruralidade, pois, embora se estabeleçam as mesmas diferenças entre estes mundos a forma de olhar para estas distintas realidades não se baseia mais na contradição, no bom ou ruim, tradicional ou atrasado, mas no que uma pode favorecer a outra, ajudando, muitas vezes, as debilidades encontradas em cada um dos espaços.

Assim, o que acontece no rural não é a inclusão de novos elementos, mas sim a atribuição de outros valores e funções a elementos já existentes, que sofrerão mudanças conforme a realidade em que se insiram.

Ou seja, estas transformações que atribuem ao rural novos valores que alicerçam estes espaços em bases não só econômicas, mas também socioculturais e ambientais, não se apresentam com a mesma magnitude em todos os espaços rurais, diferindo em intensidade e forma. Nesta perspectiva Maria José T. Carneiro (1998, p. 148) defende que: 
[...] é importante considerar que o "campo" não está passando por um processo único de transformação em toda a sua extensão. Se as medidas modernizadoras sobre a agricultura foram moldadas no padrão de produção (e de vida) urbano-industrial, seus efeitos sobre a população local e a maneira como esta reage a tais injunções não são, de modo algum, uniformes, assim como tais medidas não atingem com a mesma intensidade e proporções as diferentes categorias de produtores. Nesse sentido não se pode falar de ruralidade em geral; ela se expressa de formas diferentes em universos culturais, sociais e econômicos heterogêneos.

Observa-se assim, que não se pode considerar estas mudanças, anteriormente descritas, em todo e qualquer espaço rural, pois a realidade do mundo rural, em que se busca traçar caminhos alternativos tem diferentes ramificações, algumas mais curtas, outras mais longas. Em alguns casos apresenta maior ou menor dificuldade, sendo ainda que nem sempre os atores envolvidos estarão dispostos ou interessados em promover mudanças.

Sobre os novos caminhos possíveis para as zonas rurais, cabe ressaltar Veiga (2003, p. 80), que dá ênfase para o meio rural como possível preservador dos patrimônios natural e cultural, ressaltando que os espaços rurais têm "a capacidade de valorizar as 'amenidades' presentes em territórios que puderam evitar ou impedir a degradação de seus patrimônios natural e cultural pelas forças altamente destrutivas e poluentes". O autor coloca que dentre as amenidades a serem encontradas no rural estão fragmentos de natureza intocada, paisagens cuidadosamente manejadas, bem como antigas relíquias.

Outros aspectos relevantes no contexto das novas ruralidades são ressaltados por Carneiro (1998), ao relatar quais mudanças estão ocorrendo no cenário brasileiro. Conforme esta autora existe dois conjuntos de fenômenos no país que se destacam: um é o fenômeno da pluriatividade e o outro é a procura por formas de lazer no campo. Nesse contexto, cabe salientar Marafon (2006) que afirma que o turismo rural ao vender a força de trabalho do agricultor denota-lhe um caráter pluriativo.

Sobre as visões que circundam o espaço rural brasileiro, também se destaca a percepção de Wanderley (2001, p. 31), a qual ressalta que:

A sociedade brasileira parece ter hoje um olhar novo sobre o meio rural.
Visto sempre como a fonte de problemas - desenraizamento, miséria,
isolamento, currais eleitorais etc. - surgem, aqui e ali, indícios de que o meio
rural é percebido igualmente como portador de 'soluções'. Esta percepção
positiva crescente, real ou imaginária, encontra no meio rural alternativas
para o problema do emprego (reivindicação pela terra, inclusive dos que dela 
haviam sido expulsos), para a melhoria da qualidade de vida, através de contatos mais diretos e intensos com a natureza, de forma intermitente (turismo rural) ou permanente (residência rural) e através do aprofundamento de relações sociais mais pessoais, tidas como predominantes entre os habitantes do campo.

Estas mudanças em torno do rural brasileiro ocorrem, em parte, como consequência trazida pelo processo de mecanização e integração da agricultura a complexos industriais, que fizeram com que os sistemas de produção sofressem fortes impactos, que vieram a alterar as funções atribuídas aos espaços rurais. Consequentemente provoca uma ruptura com a visão de desenvolvimento agrário clássico, sobretudo a visão vinculada à agricultura familiar. Surgem assim debates sobre as novas ruralidades, onde se deixa de lado a visão produtivista tradicional, e passa-se a incorporar às questões de desenvolvimento aspectos de qualidade de vida da população rural e preservação dos recursos naturais. Pois, passa a se configurar nos espaços rurais uma "nova paisagem" onde: o rural deixa de ser vinculado somente à produção de bens primários e passa a cumprir outras funções; a divisão do trabalho familiar sofre mudanças; a variável ambiental passa a ter maior relevância dentro das políticas de desenvolvimento agrário etc. (MATTEI, 2004).

Complementado, Mattei (2004) ressalta ainda que os debates sobre as novas ruralidades abordam questões voltadas à retomada de uma série de valores e costumes rurais que vinham se perdendo, enfocando ainda, novas funções atribuídas ao rural. Sobre as novas concepções de rural Moreira (2007, p. 90) destaca que:

O conceito de rural e a política e prática associadas ao mundo rural poderiam, assim, estar carregando a incorporação de cuidados ambientais, o cuidado com os direitos básicos da cidadania (alfabetização, saúde e alimentação etc.), a pluriatividade (atividades rurais e urbanas exercidas no espaço rural) e uma possível multifuncionalidade do território (defesas dos patrimônios naturais e culturais).

Essas mudanças configuradas no interior do rural brasileiro, a exemplo da Europa, vão propiciar a emersão de novas funções e valores exploradas, agora, como potencialidades turísticas, nas perspectivas de promoverem mudanças para as comunidades rurais. Abandona-se assim a visão do rural agrícola, e concebe-se agora um rural multifuncional, em que elementos como paisagem e cultura ganham grande destaque. 


\subsection{O TURISMO CONTRIBUINDO PARA A VALORIZAÇÃO DO RURAL}

Nesse contexto de novas ruralidades, em que novas significações traçam o papel dos espaços rurais na sociedade contemporânea, uma atividade que ganha grande destaque, por conseguir incorporar os diversos papéis atribuídos aos espaços e comunidades rurais, é o turismo.

Contudo, no que concerne a definição de turismo rural, há uma diversidade de terminologias que permeiam a discussão conceitual sobre a atividade. Para alguns autores o turismo rural consiste em toda e qualquer atividade de lazer praticada no espaço rural, para outros se caracteriza como um tipo de turismo, que contempla o modo de vida rural, apresentando vínculo com a produção e favorecendo a agregação de valor aos produtos locais.

Para os autores que vislumbram o turismo rural a partir da segunda vertente esboçada, o turismo em áreas rurais se caracteriza por toda e qualquer atividade turística praticada nesses espaços, independente de sua relação com as atividades propriamente agrícolas. Encontram-se assim nos espaços rurais o estabelecimento de diversos segmentos turísticos, tais como: turismo rural, que se caracteriza pela prática de atividades recreativas que estejam vinculadas às lidas e aos costumes típicos do rural; o turismo ecológico, que tem suas atividades vinculadas à natureza; turismo cultural, que busca a aproximação do turista com uma determinada cultura; turismo histórico, em que o foco é resgatar aspectos da história do espaço visitado o qual normalmente está intimamente vinculado ao turismo cultural, entre outras modalidades de turismo que podem ser praticadas em espaços rurais. Estas modalidades de turismo podem ser exploradas conjuntamente ou individualmente. Assim, Tulik (2003) ao abordar o conceito da terminologia "Turismo em Espaços Rurais", coloca este como a totalidade das atividades turísticas desempenhadas no meio rural.

Das diversas definições utilizou-se, para fins de apreciação analítica, a conceituação traçada pelo Ministério do Turismo (BRASIL, 2003, p. 11), a qual destaca que "Turismo Rural é o conjunto de atividades turísticas desenvolvidas no meio rural, comprometidas com a produção agropecuária, agregando valor a produtos e serviços, resgatando e promovendo o patrimônio cultural e natural da comunidade". 
Em concordância e numa busca por estabelecer alguns princípios norteadores para o planejamento do turismo rural, Zimmermann (1996) ressalta que esta atividade em espaços rurais deve ser concebida sob a ótica de valorização das peculiaridades que diferenciam o rural de núcleos urbanos. Destaca como pontos principais para o seu planejamento a valorização da:

\begin{abstract}
IDENTIDADE PRÓPRIA: Significa o respeito pelas características do ambiente como um todo. A preservação da paisagem, o tipo de atividades produtivas, a cultura étnica do proprietário e do local, a arquitetura das edificações da propriedade são os fatores que darão identidade própria ao local a ser trabalhado; AUTENTICIDADE: Diretamente ligada à identidade, deve ser espontânea. É preciso assumir o "clima" local; HARMONIA AMBIENTAL: Significa preservar e restaurar o ambiente como um todo. Aproveitar ao máximo a estrutura disponível e todas as ampliações e alterações que se fizerem necessárias devem obedecer o perfil arquitetônico existente, buscando um equilíbrio harmônico; PRESERVAÇÃO DAS RAÍZES: A cultura, em toda sua plenitude, deve estar presente no contexto. $\mathrm{Na}$ maioria das vezes hábitos e costumes estão esquecidos pelo tempo. É necessário que se resgate e viabilize ao turista vivenciar todas as formas culturais locais, tais como: gastronomia, uso de objetos, artesanato, móveis, arquitetura, etc.; DIVULGAÇÃO DOS COSTUMES: Forma prática de mostrar as raízes e a cultura local das mais variadas formas. Serve também como lazer aos turistas a apresentação de grupos folclóricos, músicos, dançarinos, etc.; ATENDIMENTO FAMILIAR: Este é o grande diferencial dos sistemas tradicionais de hospedagem: o atendimento familiar, que promove um forte relacionamento humano de amizade. (ZIMMERMANN, 1996, p. 28-29).
\end{abstract}

Vislumbra-se a partir dos conceitos ou princípios apresentados, que o turismo rural está alicerçado nas particularidades do rural, tendo na cultura, na natureza, no patrimônio, ou seja, na sua identidade seus alicerces.

\title{
4 CONTEXTUALIZANDO O LUGAR DE PESQUiSA: A MACROZONA “RURURBANA" DE PORTO ALEGRE
}

O município de Porto Alegre (figura 1), capital do estado do Rio Grande do Sul, está inserido na Região Metropolitana de Porto Alegre, a qual apresenta a maior densidade demográfica do estado (RIO GRANDE DO SUL, 2002). 


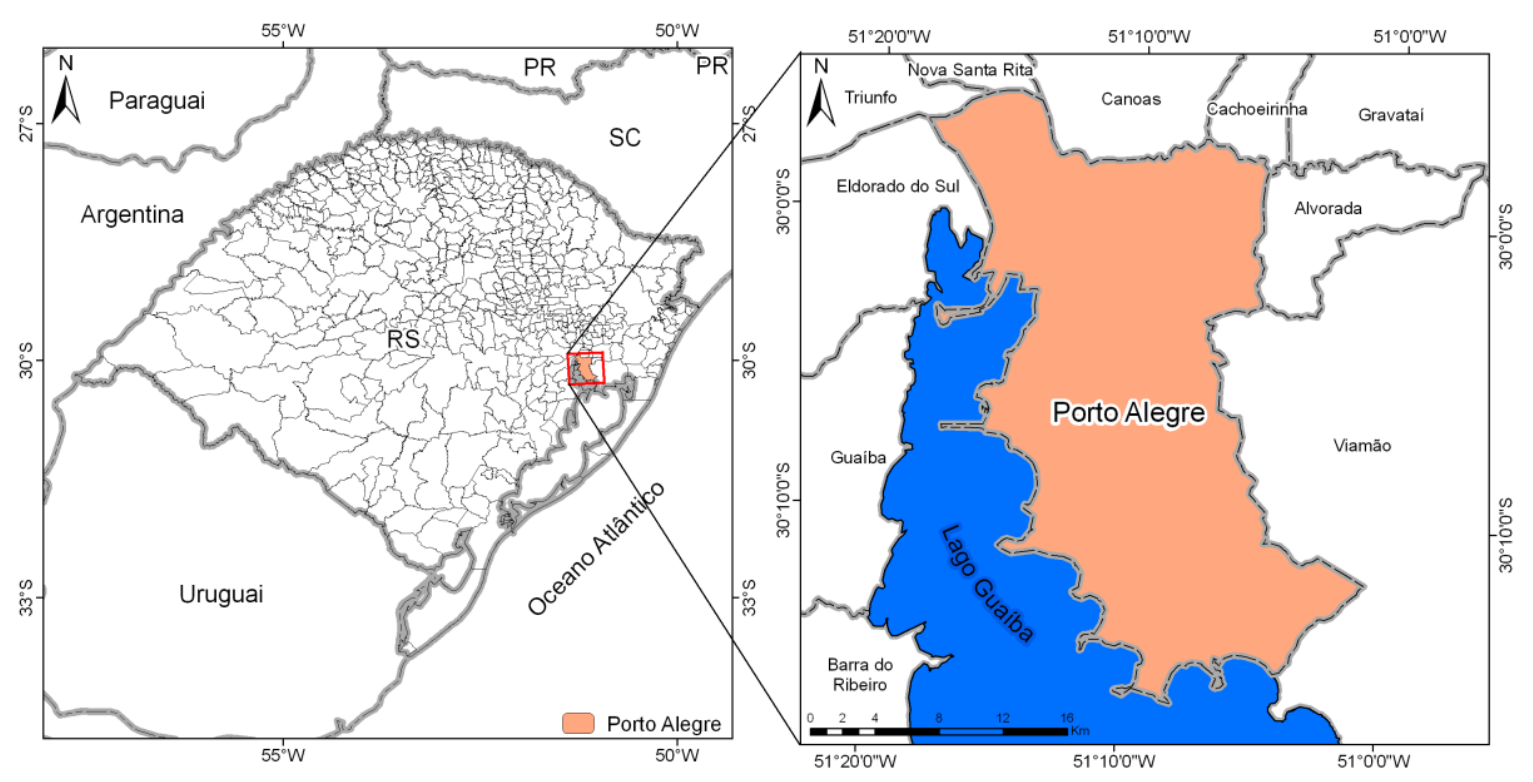

FIGURA 1 - LOCALIZAÇÃO DO MUNICÍPIO DE PORTO ALEGRE EM RELAÇÃO AO ESTADO DO RIO GRANDE DO SUL. FONTE: BASE CARTOGRÁFICA DO IBGE. ELABORAÇÃO: TEIXEIRA, A. R.

A área em que estão localizadas as propriedades rurais de Porto Alegre está situada no sul do município, na Macrozona "Cidade Rururbana", conforme designado pelo segundo Plano Diretor de Desenvolvimento Urbano Ambiental (PDDUA), implementado em 1999 (PORTO ALEGRE, 1999). De acordo com o artigo 29 do PDDUA, o qual estabelece a divisão de Porto Alegre em macrozonas,

[a] Cidade Rururbana (Macrozona 8) - é caracterizada pela presença de zonas de produção de alimentos e criação de animais junto a áreas residenciais com baixo número de moradores, espalhadas pela região. Nela existem, também, os núcleos de Belém Novo, Belém Velho e Lami, mais ocupados e com características de cidade intensiva. Dada a predominância de valores naturais, como os morros e a orla, seu uso deverá ser incentivado, também, para o lazer e o turismo ecológico. (PORTO ALEGRE, 1999, s./n.).

O termo rururbano, utilizado para definir a área em estudo, remete ao conceito de rurbanização, o qual é permeado por uma questão socioespacial, que engendra a ideia de intersecção entre os elementos que caracterizam o rural e o urbano, fenômeno sucedido pela tomada do campo pela cidade, sendo concebido como uma forma de desenvolvimento por Gilberto Freyre, o qual defende:

[...] uma política social que não se extreme nem na urbanização nem na ruralização da comunidade pernambucana mas se esmere na sua rurbanização. Ou seja: no equilíbrio, dentro dessa comunidade complexa e já 
antiga e ecológica e sociologicamente diversa pelos seus vários espaços naturais e culturais que devemos procurar transformar de antagônicos em complementares - agrários, pastoris, industriais - dos valores e estilos urbanos com os valores e estilos rurais. Mais que equilíbrio: interpretação. Compenetração. Precisamos formar e desenvolver aqui uma mentalidade rurbana, na concepção por assim dizer conjugal, de rurbanidade. [...] venho, no Brasil, procurando desenvolver para caracterizar situação mista, dinâmica e, repito, conjugal, fecundamente conjugal: terceira situação desenvolvida pela conjugação de valores das duas situações originais e às vezes contrárias ou desarmônicas, quando puras. (FREYRE, 1982, p. 82).

É a partir desse discurso, da rurbanidade, de conjugação entre o campo e a cidade, que o rural de Porto Alegre passou a ser visto e planejado, a partir de 1999. Contudo, ao invés da interação entre esses espaços, percebe-se uma constante tomada do espaço rural pelo urbano, em que os valores e estilos citadinos se sobrepõem aos valores e estilos rurais e, consequentemente, não interagem entre si.

A conformação do rural para rurbano no município de Porto Alegre denota o aparecimento de um continuum, pois de acordo com Schneider (2003, p. 7-8) é "o processo de erosão das diferenças espaciais entre o rural e o urbano, indicando-se o aparecimento de um continuum entre ambos que seria a expressão espacial do processo de rurbanização".

É nesse contexto de tomada do rural pelo urbano que o Roteiro Caminhos Rurais, foco de abordagem deste trabalho, está alocado. Podendo desempenhar importante papel em meio à desarticulação da ruralidade em Porto Alegre, divulgando esse espaço e suas funções, promovendo sua valorização frente à população urbana local. Desta forma, favorecendo a relação entre o rural e o urbano, enquanto um processo interativo e não de tomada de um espaço pelo outro.

Pode-se indicar que o aparecimento dessa atividade não agrícola no espaço rural é mais um elemento que evidencia a formação de um continuum entre o rural e o urbano no município de Porto Alegre, pois de acordo com Schneider (2003, p. 8):

\footnotetext{
A idéia é que à medida que avança o crescimento das atividades não agrícolas nos espaços rurais estes se tornariam cada vez mais semelhantes aos urbanos, o que acabaria com as especificidades de um em relação ao outro fazendo aparecer um espaço rurbano, que seria formado por um continuиm entre o rural e o urbano. (SCHNEIDER, 2003, p. 8, grifo do autor).
}

Assim, a adentrada do turismo no espaço rural, ao mesmo tempo em que pode colaborar para valorização da ruralidade, divulgando as práticas e costumes rurais, 
colabora para aproximar o rural do urbano, diminuindo as especificidades existentes entres estes espaços, por ser esta uma atividade oriunda do meio urbano.

Portanto, cabe aqui retomar as apreciações de Wanderley (2001) sobre as duas perspectivas de continuum, uma primeira centrada no urbano, em que, na relação de aproximação entre rural e urbano, o campo estaria fadado ao desaparecimento pela expansão da cidade, e uma segunda vertente da perspectiva do continuum, que se afasta mais da visão dicotômica, a qual defende que mesmo com a aproximação espacial e com a diminuição das diferenças entre rural-urbano, as peculiaridades de ambos não desaparecem, o que reafirma a existência do rural.

Contrapondo tais perspectivas à realidade analisada, percebe-se que o continuum que vem se afirmando no município de Porto Alegre está próximo da primeira perspectiva salientada, visto que a crescente tomada da cidade pelo espaço rurbano, que ainda apresenta traços de ruralidade, está em constante degradação, ou seja, o rurbano de Porto Alegre afasta-se cada vez mais do rural e aproxima-se cada vez mais do

urbano. É nessa perspectiva que pode se pensar o turismo enquanto elemento capaz de atuar na valorização das ruralidades presentes neste espaço, contribuindo para a composição de outro continuum, que se aproxime da segunda perspectiva traçada, em que a aproximação entre o rural e o urbano não evidenciem uma tomada dos elementos que caracterizam tais espaços, mas sim a interação entre os mesmos.

Para tanto, mostrar-se-á posteriormente como o turismo vem atuando na valorização da ruralidade, numa perspectiva de análise daqueles que aderiram ao turismo como meio de colaborar para a manutenção de suas propriedades.

\section{O ROTEIRO TURÍSTICO CAMINHOS RURAIS E A VALORIZAÇÃO DA RURALIDADE EM PORTO ALEGRE}

Nesta seção são expostos os resultados de pesquisa e análise, os quais foram divididos em duas partes, uma referente a descrição e apresentação do roteiro estudado e outra de descrição dos elementos que denotam a valorização ou não da ruralidade a partir do turismo. 


\subsection{O ROTEIRO TURÍSTICO CAMINHOS RURAIS}

O marco inicial do turismo na zona "rururbana" de Porto Alegre data de 1999, quando alguns agricultores começaram a aderir à atividade turística por meio do incentivo de estudantes de turismo. Essas atividades eram praticadas isoladamente em algumas propriedades que hoje compõem o roteiro turístico Caminhos Rurais, que foi lançado em 2005 por incentivo da Prefeitura Municipal de Porto Alegre (PORTO ALEGRE, 2005).

De acordo com a mesma fonte acima o roteiro está distribuído por diversos bairros da Macrozona "Rururbana" de Porto Alegre, sendo constituído, atualmente, por trinta e dois empreendimentos, que compreendem uma diversidade de tipos de turismo no espaço rural, os quais são: ecoturismo, turismo rural, turismo cultural, turismo de estudos e intercâmbios e turismo de negócios e eventos; além dos serviços e equipamentos que também constituem o roteiro.

De acordo com COODESTUR (2010) o turismo rural é dividido em três temáticas que são: o turismo agroecológico, o turismo de flores e plantas ornamentais e o turismo equestre. $\mathrm{O}$ ecoturismo, outro tipo de turismo que vem sendo muito praticado nos espaços rurais, é propiciado pela presença de recursos naturais ainda conservados, os quais conformam grandes áreas naturais. Tendo como atividades, caminhadas, trilhas e observação. O turismo de estudos e intercâmbio, caracterizado por práticas pedagógicas direcionadas a aprendizagem, é direcionado tanto para estudantes do ensino fundamental e médio, quanto para estudantes universitários, sendo praticado, em sua maioria, por propriedades direcionadas a produção agroecológica e direcionadas para a conservação da natureza e paisagem local. As tematizações apresentadas para o roteiro a partir desse tipo turístico são: Vivência/Pedagógico e Turismo Científico. Já o turismo cultural praticado no Caminho Rurais, caracterizado pelas temáticas do enoturismo, turismo religioso e turismo esotérico, apresenta-se em menor proporção, mas caracteriza a diversidade do roteiro. Outro tipo de turismo que é evidenciado no roteiro é o de Negócio e Eventos, o qual é caracterizado pelo recebimento de grupos com interesses profissionais ou sociais e que buscam esses espaços para realizar de reuniões, confraternizações, retiros, etc. Por fim, destaca-se que o roteiro é composto por outros empreendimentos que são caracterizados como serviços e equipamentos, os 
quais aparecem em apoio aos atrativos e oferecem serviços de alimentação, hospedagem e pontos de venda.

\subsection{A VALORIZAÇÃO DA RURALIDADE EM PORTO ALEGRE A PARTIR DO TURISMO}

Para a análise da valorização do rural a partir do turismo, consideraram-se aspectos culturais, de produção e produtos, bem como do espaço, considerando seu ambiente e paisagem, elementos que configuram a ruralidade o diferenciando do que não é rural. Para tanto, cabe retomar Moreira (2007, p. 228), o qual enfatiza que "as ruralidades só podem existir e serem pensadas a partir de suas relações com algo que a cultura significa como não-rural".

A revalorização do rural a partir da cultura local é evidenciada a partir da gastronomia e do artesanato, das festividades, que comumente se ressaltam como atrativos da atividade turística no meio rural, por remeterem às peculiaridades locais. Muitas vezes esses elementos estavam perdidos no tempo, não eram mais cultuados ou praticados e, em função do turismo, acabam sendo retomados, e inserem-se novamente na rotina dos que trabalham com o turismo no campo.

No caso estudado não evidenciou-se a revalorização da cultura local, que poderia ser gerada a partir da promoção de intercâmbio cultural trazendo a valorização dos hábitos locais. Embora algumas das propriedades estejam voltadas para a gastronomia, a mesma não apresenta vínculo com uma culinária local, típica de seus habitantes. Outro aspecto que pode remeter à cultura local, que é o artesanato, não foi evidenciado dentre as práticas vinculadas para o turismo.

Conforme o corroborado nas entrevistas isso acontece porque a Macrozona Rururbana de Porto Alegre não apresenta uma cultura específica e homogênea, pois a composição da população local tem diversas origens, o que não favoreceu a manutenção de hábitos que poderiam fazer da cultura local um atrativo turístico, ou mesmo que pudessem ser resgatados a partir dele.

Já o aspecto de produção e produtos como meio de valorização do rural aparece como ponto importante. Pode ser entendido como valorização da produção local, do trabalho agrícola e mesmo dos produtos locais. Muitas vezes o turismo pode estimular o surgimento ou fortalecimento de agroindústrias familiares. 
Nos casos estudados, este aspecto é ressaltado, principalmente, pela valorização do produto para o consumo, pois como muitos dos proprietários incluídos na pesquisa participam de feiras na cidade de Porto Alegre, os entrevistados destacaram que muitos dos seus consumidores, nestas feiras, conheceram seus produtos a partir das visitações nas propriedades como turistas. Quanto à valorização dos modos de produção, ou seja, do trabalho no meio rural, esta não é explicitada pelos agricultores.

Por fim, observa-se como aspecto relevante na revalorização da ruralidade a valorização do rural enquanto espaço, o qual se apresenta, normalmente, bem menos degradado do que espaços urbanos. Esses aspectos são destacados a partir da contemplação de uma paisagem que, normalmente, reúne uma natureza menos degradada que nos espaços urbanos, junto a elementos agrícolas e com poucas edificações.

Este item mostrou-se bastante relevante para os proprietários rurais entrevistados, pois, como as propriedades estão próximas de um cenário urbano, de grande aglomeração de pessoas e construções, onde pouco se observa elementos naturais, os turistas mostram-se deslumbrados ao descobrirem que, neste mesmo município, existem espaços que compreendem uma natureza bastante conservada.

Desta forma, mostra-se relevante a relação entre o turismo e os elementos da paisagem e do espaço rururbano de Porto Alegre por possibilitar aos citadinos conhecer e observar outra face do município que se apresenta menos degradada ambientalmente. Desta forma, podem perceber o quanto um local com menos infraestrutura e mais natureza pode favorecer a qualidade de vida, despertando nos citadinos outros valores. O conhecimento desse espaço pelos que vivenciam o lado rural de Porto Alegre pode colaborar para a valorização e por consequência para a conscientização de manutenção desse espaço com as funções rurais desempenhadas, visto que tal lugar vem sofrendo com a constante expansão urbana do município de Porto Alegre.

\section{CONCLUSÃO}

Procurou-se no decorrer desse trabalho analisar como o turismo rural vem contribuindo para a valorização do rural e da ruralidade, tendo como foco de estudo a Rota Turística Caminhos Rurais, inserida no município de Porto Alegre. Contudo, a 
análise da valorização da ruralidade nesse município denota-se difícil, visto que em tal contexto encontrou-se um espaço rurbano, instituído em 1999 em detrimento do espaço rural do município.

Nesse espaço a ruralidade vem sendo desarticulada por um processo de aproximação do rural com o urbano, em que se observa não a interação entre esses espaços, mas a tomada do rural pelo urbano, em que antigos espaços de produção agropecuária vêm adquirindo, principalmente, a função residencial.

Contudo, a perpetuação do turismo no espaço rural, ao mesmo tempo em que pode colaborar para valorização da ruralidade, divulgando as práticas e costumes rurais, colabora para aproximar o rural do urbano, diminuindo as especificidades existentes entres estes espaços, porque esta é uma atividade oriunda do meio urbano.

No que concerne à valorização da ruralidade, que ainda caracteriza a zona rurbana do município de Porto Alegre, observa-se que os elementos mais valorizados são os elementos espaciais como a natureza local, a partir da contemplação da paisagem; produção local, o que remete às funções tradicionais do rural; e a valorização dos produtos, consumidos em feiras na cidade e que são divulgados a partir de visitações ao roteiro.

Portanto, o turismo apresenta-se como uma via dupla, pois assim como valoriza aspectos tradicionais do rural, suas funções, seus modos de vida, também sustenta a aproximação do rural com o urbano, ou seja, a formação de um continuum entre esses espaços, ao ser mais uma atividade originada no urbano se apropriando do rural e atuando na transformação das ruralidades. Nessa perspectiva, vê-se o turismo enquanto elemento capaz de atuar na valorização das ruralidades presentes neste espaço, contribuindo para a composição de um continuum, que atue na aproximação entre o rural e o urbano que gera a interação dos elementos de cada espaço, mas não a tomada de um pelo outro.

\section{REFERÊNCIAS}

ALMEIDA, J. A. Pesquisa em Extensão Rural: um manual de metodologia. Brasília: ABEAS, 1989. 
BAGLI, P. Rural e Urbano: harmonia e conflito na cadência da contradição. In: Cidade e Campo: relações e contradições entre urbano e rural. São Paulo: Expressão Popular, 2006.

BAPTISTA, F. O. O Rural depois da Agricultura. In: Desenvolvimento e Território: espaços rurais pós-agrícolas e novos lugares de turismo e lazer. Lisboa: M2 - Artes Gráficas, 2006. p. 85 - 105.

BRASIL. Ministério do Turismo. Diretrizes para o Desenvolvimento do Turismo Rural no Brasil. Brasília: 2003.

CARNEIRO, M. J. T. Ruralidade: novas identidades em construção. Estudos Sociedade e Agricultura. 1998: p. 53-75. Disponível em: <http://bibliotecavirtual.clacso.org.ar/ar/libros/brasil/cpda/estudos/onze/zeze11.htm>.

Acesso em: 10/02/2011.

COODESTUR Cooperativa de Formação e Desenvolvimento do Produto Turístico. Projeto de Apoio a Iniciativas de Turismo de Base Comunitária nos Caminhos Rurais de Porto Alegre: etapa - diagnóstico turístico dos Caminhos Rurais instrumentos de pesquisa. Porto Alegre, 2010.

FREYRE, G. Rurbanização: o que é? Recife: Massanagana, 1982.

INSTITUTO BRASILEIRO DE GEOGRAFIA E ESTATÍSTICA (IBGE). Censo 2010. Disponível em: <http://www.censo2010.ibge.gov.br> Acesso em: 20/03/2011.

MARAFON, G. J. Agricultura Familiar, Pluriatividade e Turismo Rural: reflexões a partir do território fluminense. Campo-Território: revista de Geografia Agrária, Uberlândia, v. 1, n. 1, p. 17-60, fev. 2006.

MATTEI, L. Turismo Rural e Ocupações Não-agrícolas: o caso de Santa Catarina. In: CAMPANHOLA, C.; GRAZIANO da SILVA, J. (Orgs.). O Novo Rural Brasileiro: novas atividades rurais. Brasília: Embrapa Informação Tecnológica, 2004. V. 6. p. 183218.

MOREIRA, R. J. Terra, Poder e Território. São Paulo: Expressão Popular, 2007.

PORTO ALEGRE. Secretaria de Planejamento Municipal. Plano Diretor de Desenvolvimento Urbano Ambiental - PDDUA. 1999. Disponível em: <http://www.portoalegre.rs.gov.br/planeja/spm/default.htm> Acesso em: 22/11/2010.

PORTO ALEGRE. Secretaria Municipal De Turismo. Caminhos Rurais de Porto Alegre. Porto Alegre, 2005.

RIO GRANDE DO SUL. Secretaria de Coordenação e Planejamento. Atlas Socioeconômico: Estado do Rio Grande do Sul. 2. ed. Porto Alegre: Rio Grande do Sul. Secretaria de Coordenação e Planejamento, 2002. 
SARACENO, E. O Conceito de Ruralidade: problemas e definições em escala européia. (Unine: CRES) Trad. Ângela Kageyama.1996.

SCHNEIDER, S. Rurbanização e Pluriatividade: o mercado de trabalho não-agrícola e a pluriatividade das famílias em áreas rurais (um estudo de caso). In: CARVALHO, F. de; GOMES, M. M.; LÍRIO, V. S. (Org.). Desigualdades Sociais: pobreza, desemprego e questão agrária. Viçosa, 2003, p. 151-188.

TULIK, O. Turismo Rural. São Paulo: Aleph, 2003.

VEIGA, J. E. da. Cidades Imaginárias: o Brasil é menos urbano do que se calcula. $2^{\mathrm{a}}$ ed. Campinas, SP: Autores Associados, 2003.

VEIGA, J. F. F. Território e Desenvolvimento Local. Oeiras - Portugal: Celta Editora, 2005 .

WANDERLEI, M. N. B. A Ruralidade no Brasil Moderno: por um pacto social pelo desenvolvimento rural. In: Una Nueva Ruralidad en América Latina? Buenos Aires: 2001 .

ZIMMERMANN, A. Turismo Rural: um modelo brasileiro. Florianópolis: Ed. do Autor, 1996.

Recebido em: 07-12-2011.

Aprovado em: 07-01-2012. 